Research Article

\title{
Carbon Dioxide Emission Measurement and Its Spatiotemporal Evolution of Tourism Industry in Heilongjiang Province, China
}

\author{
Zi Tang $\mathbb{i D}^{1,2}$ and Tianyue Huang ${ }^{1}{ }^{1}$ \\ ${ }^{1}$ School of Tourism and Cuisine, Harbin University of Commerce, Harbin 150028, China \\ ${ }^{2}$ Postdoctoral Station of Business Administration, Harbin University of Commerce, Harbin 150028, China \\ Correspondence should be addressed to Zi Tang; tz09@163.com
}

Received 14 July 2021; Revised 20 August 2021; Accepted 23 August 2021; Published 3 September 2021

Academic Editor: Antonio Donateo

Copyright $\odot 2021 \mathrm{Zi}$ Tang and Tianyue Huang. This is an open access article distributed under the Creative Commons Attribution License, which permits unrestricted use, distribution, and reproduction in any medium, provided the original work is properly cited.

\begin{abstract}
This study analyses the composition and evolution of carbon dioxide emissions from the tourism industry in Heilongjiang Province and its 12 regions by the tourism consumption stripping coefficient method and calculates the decoupling relationship between the carbon dioxide emissions and economic growth of tourism from 2010 to 2019. The empirical results are as follows. (1) From 2010 to 2019, carbon dioxide emissions from Heilongjiang Province's tourism industry and its subsector increased steadily, of which the tourism industry accounted for a relatively large amount of carbon dioxide emissions in "Transport, Storage, and Post." (2) Time series analysis reveals that the carbon dioxide emissions of tourism basically show an increasing trend and there are still multiple decoupling relationships with economic growth. Expansive decoupling and weak decoupling have occurred more frequently. (3) Spatial analysis reveals that the carbon dioxide emissions of the regional tourism industry show a fluctuating upward trend. The tourism industry in Harbin has significantly higher carbon dioxide emissions than in other regions. In addition, this study provides feasible suggestions and countermeasures for low-carbon tourism development in Heilongjiang Province. The findings are considered useful in future planning of energy conservation and emission reduction in Heilongjiang Province and the regional tourism industry.
\end{abstract}

\section{Introduction}

Global climate change is one of the largest, most extensive, and most far-reaching challenges facing mankind in the 21st century. Continued greenhouse gas emissions will cause further global warming and lead to changes in all components of the climate system. According to the IPCC Working Group I report, Climate Change 2021: the Physical Science Basis, emissions of greenhouse gases from human activities are responsible for approximately $1.1^{\circ} \mathrm{C}$ of warming since industrialization, and global temperature is expected to reach or exceed $1.5^{\circ} \mathrm{C}$ of warming [1]. Global warming leads to rising sea levels, extreme weather is everywhere, and global climate change has become an important factor hindering sustainable and high-quality social and economic development. As an important greenhouse gas, carbon dioxide emission due to energy consumption is one of the important factors in aggravating global climate change [2].
As for the tourism industry, due to the overexploitation of resources and energy consumption, it also produces a certain amount of carbon dioxide emissions, which has exerted a growing influence on the ecological environment and climate change [3].

The COVID-19 epidemic has affected all walks of life in China's economy, and the highly market-oriented tourism industry is one of the industries that has suffered the most. Consumer service industries such as industrial production, catering, and tourism are greatly affected, and the whole society is in a passive low-carbon lifestyle. That is to say, the decline in carbon dioxide emissions caused by the epidemic is temporary, and the short-term decline in emissions is not abnormal. After the epidemic, energy conservation and emission reduction still have a long way to go. With the epidemic being under control in China, various production operations have begun to gradually recover, and carbon dioxide emissions are gradually rising. If the energy system 
structure is not changed, emissions will return to their original levels after the epidemic. With the effective control of the COVID-19 epidemic, tourist attractions have opened their doors to welcome visitors, and the tourism economy has gradually recovered. The vigorous development of the tourism industry will also affect changes in the economy and the ecological environment. President $\mathrm{Xi}$ promised the world at the UN General Assembly and the Climate Ambition Summit that China will increase its nationally determined contribution to climate change-aim to have $\mathrm{CO}_{2}$ emissions peak before 2030 and achieve carbon neutrality before 2060 [4]. This not only clarifies the goals for China's efforts to tackle climate change but also provides a driving force for the further development of the carbon dioxide emission rights market mechanism. Therefore, while the rapid development of the tourism industry promotes rapid and sound economic development, environmental protection must also be strengthened. Heilongjiang Province has always attached great importance to tourism development, and the tourism industry has injected new vitality into the development of Heilongjiang's consumer market. In 2019, Heilongjiang Province received 220 million domestic and foreign tourists and achieved income of tourism at 268.4 billion yuan. Income of domestic tourism and foreign tourism increased by $19 \%$ and $19.6 \%$, respectively [5].

Scholars have so far measured the carbon dioxide emissions of the tourism industry mainly in three dimensions. First of all, in the selection of research objects, the current research on the carbon dioxide emissions calculation of tourism is mostly discussed from the national scale. Azam et al. [6] examined the impact of the entry of tourists from Malaysia, Thailand, and Singapore on the environmental pollution caused by carbon dioxide emissions from 1990 to 2014. Wu and Shi [7] discussed the formulation of emissionreduction policies in China's tourism industry and the preliminary estimation of energy consumption and carbon emissions in China's tourism industry. Zha et al. [8] estimated the carbon dioxide emissions of China's tourism industry from 2005 to 2015 . Tang et al. [9-13] estimated the $\mathrm{CO}_{2}$ emissions of tourism between individual provinces. $\mathrm{Han}$ and $\mathrm{Wu}[14]$ estimated carbon dioxide emissions from tourism in parts of China. Coopera and McCulloughb [15] quantified the carbon footprint of the 2019 National College Sports Association Men's Basketball Championship. Gühnemann et al. [16] reviewed and evaluated the current state of knowledge about the complex relationship between the tourism industry and climate change in the Austrian case study. Saviolidis et al. [17] developed a national indicator set specifically for Iceland to assess its ability to capture the impact of tourism on environmental sustainability. Filimonau et al. [18] developed a new method for comprehensive assessment of greenhouse gas emissions based on the British tourism market and tested its applicability. Paiano et al. [19] analysed the carbon dioxide emissions and waste associated with water and beverage packaging for all passengers visiting Italian ports on cruise ships for two years.

Secondly, with regard to the measurement method of the tourism industry's carbon dioxide emissions, based on existing research, scholars have measured and analysed the tourism industry's energy consumption and carbon dioxide emissions from different research perspectives. The estimation methods include production method and expenditure method, input-output method, extended tourism satellite record method, "bottom-up" model based on process analysis, and "top-down" model based on inputoutput analysis. Kelly and Williams [20] applied a "bottomup" approach to assess the impact of greenhouse gas emissions in Whistler, British Columbia. Sun [21] used the "bottom-up" method to estimate Shanghai's carbon dioxide emissions of tourism from 1997 to 2017. Wang and Xie [22] used Kaya identities to estimate Shenzhen's carbon dioxide emissions. Zhang and Liu [23] used the tourism consumption stripping coefficient method to estimate the carbon dioxide emissions of the tourism industry in China's coastal regions. The carbon dioxide emissions of the tourism industry are estimated by different methods, and the results are different. According to the definition of tourism, this study uses the consumption coefficient method to calculate and obtain more accurate results.

In addition, scholars are also concerned about the relationship between the carbon dioxide emissions of the tourism industry and its economic growth. Akadiri et al. [24] studied the relationship between the carbon emissions of 16 tourist island countries and the growth of international tourism from 1995 to 2016 and proved that there is a twoway causal relationship between globalization and carbon emissions. Wang et al. [25] believed that there is a long-term cointegration relationship between economic growth in the tourism industry and carbon dioxide emissions. Ma et al. [26] analysed the decoupling relationship between carbon dioxide emissions and economic growth of inbound tourism. Tzeremes [27] used the time-varying method to measure the environmental Kuznets curve of 30 regions in China from 1997 to 2012.

To sum up, through literature review, it is found that the current measurement research on carbon dioxide emissions of China's tourism mainly draws on foreign bottom-up estimation methods and directly uses the accounting coefficients in foreign research results, which inevitably deviates from China's national conditions. Due to the limited statistical data, previous research direction is mainly focused on the development of the tourism industry in a certain province, and there is less research on the economic perspective of regional space. In-depth study of the temporal and spatial characteristics of carbon dioxide emissions in different regions can not only identify the key factors affecting the development of low-carbon tourism but also help formulate industrial development strategies and policies. Among them, the relevant research on the estimation carbon dioxide emissions of tourism in Heilongjiang Province is relatively early, the data in recent years are lacking, and the estimation on carbon dioxide emissions of tourism at the spatial level in the province is not yet clear.

Based on low-carbon tourism, this study focuses on the temporal and spatial distribution of carbon dioxide emissions of tourism in Heilongjiang Province from 2010 to 2019. Due to the complex composition of the tourism industry, it is also difficult to obtain tourism-related data, which makes 
it very difficult to accurately measure carbon dioxide emissions from the tourism industry. The data for this study are obtained from Heilongjiang Statistical Yearbook and China Energy Statistical Yearbook, which ensure the reliability of the data and the scientific nature of the method. The tourism consumption stripping coefficient method is used to make a preliminary estimation of the total amount and structure of the tourism industry's carbon dioxide emissions. In addition, this study obtains the characteristics of its temporal and spatial distribution changes by measuring the carbon dioxide emissions of the tourism industry. On this basis, the decoupling theory is used to obtain the relationship between the carbon dioxide emissions of the tourism industry and economic growth, and finally the development of low-carbon tourism is analysed. The results of this study can be used as a reference for follow-up research to explore the emission reduction potential of the tourism industry in Heilongjiang Province and sought to maximize the economic and environmental benefits of the regional tourism industry. On the basis of this research, relevant departments can plan and manage low-carbon tourism in Heilongjiang Province.

\section{Materials and Methods}

2.1. Data Source and Processing. The data come from Heilongjiang Statistical Yearbook and China Energy Statistical Yearbook. Due to the different statistical methods of some yearbook data before and after 2009, this study selects the tourism-related data of Heilongjiang Province from 2010 to 2019 to measure the carbon dioxide emissions of tourism. The statistical methods of data for some industries in 2018 and 2019 are completely different from previous years and are estimated based on the predicted values of previous years. Due to the limitation of statistical data, this study cannot calculate the energy consumption and emissions of all sectors in the tourism industry. According to the Heilongjiang Statistical Yearbook, the tourism industry's carbon dioxide emissions are mainly related to two parts of the tertiary industry. The category of part $A$ is "Transport, Storage, and Post," and part $B$ is "Wholesale, Retail Trade, and Catering Services." Similarly, in China Energy Statistical Yearbook: Heilongjiang Province Energy Balance Sheet (Physical Quantity), part $A$ is "Transport, Storage, and Post" and "Wholesale and Retail Trade" and "Hotels and Catering Services" are selected as part $B$ related to the tourism industry.

2.2. Consumption Stripping Coefficient. The tourism industry in a narrow sense in China mainly refers to travel agencies, hotels, coach and shipping companies, and tourism businesses that specialize in the purchase and sale of tourism products. The tourism industry in a broad sense includes all walks of life related to tourism in addition to companies that specialize in tourism business. Since China has not established data on carbon dioxide emissions classified by industries, this study uses the "tourism consumption stripping coefficient" method [28] to separate the energy consumption of Heilongjiang's tourism industry from the energy consumption of its related industries. The formula is

$$
R_{i}=\frac{T_{i}}{V_{i}}
$$

where $R_{i}$ represents the stripping coefficient of tourism consumption in industry $i, V_{i}$ represents the added value of industry $i$ [29], and $T_{i}$ represents the added value of tourism in industry $i$ ( $T_{i}$ can be obtained by multiplying the valueadded rate of industry $i$ by the income of tourism in industry $i$ ). The value-added rate of industry $i$ refers to the ratio of the added value of industry $i$ to the total output value of industry $i$.

2.3. Carbon Dioxide Emission Measurement. In formulas (3) and (4), $C$ represents the total carbon dioxide emissions of the tourism industry, $C_{i}$ represents the dioxide emissions of tourism-related industries, $E_{i j}$ represents the energy consumed by industry $i$, excluding tourism irrelevant parts, and $h_{j}$ represents the converted standard coal coefficient of energy $j$. Generally, one ton of standard coal can produce 2.66-2.72 tons of carbon dioxide. In this study, the value of $k$ is 2.45 [29], and $E_{i j}^{\prime}$ represents the amount of energy of type $j$ consumed by industry $i$. China stipulates that the calorific value per kilogram of standard coal is $7000 \mathrm{kcal}$. The calorific value of coal, oil, natural gas, and electric energy is different (see Table 1). In order to compare various energy sources to calculate and investigate their energy consumption, the standard conversion unit of standard coal is usually used.

$$
\begin{aligned}
C & =\sum C_{i}, \\
C_{i} & =\sum_{j=1}^{n}\left(E_{i j} \bullet h_{j} \bullet k\right), \\
E_{i j} & =E_{i j}^{\prime} \bullet R_{i} .
\end{aligned}
$$

2.4. Decoupling Model. This study uses a decoupling model to explain the relationship between tourism economic growth and carbon dioxide emissions of tourism. The decoupling theory is the basic theory proposed by the International Organization for Economic Cooperation and Development (OECD) to describe the blocking of the link between economic growth and resource consumption or environmental pollution. The percentage of change in carbon dioxide emissions reflects the degree of sensitivity between them [30]. The theory originally originated from the field of physics, which refers to the disconnection between two interconnected physical quantities. The Organization for Economic Cooperation and Development applies it to the environmental field and defines it as the breakdown of the link between environmental pollution and economic growth [31]. Since then, Tapio and others have further refined the decoupling model indicators to form the Tapio carbon dioxide emission decoupling indicator, which is 
TABle 1: Partial energy conversion standard coal reference coefficient.

\begin{tabular}{lc}
\hline Energy type & Converted standard coal coefficient \\
\hline Coal & $0.7143 \mathrm{kgce} / \mathrm{kg}$ \\
Gasoline & $1.4714 \mathrm{kgce} / \mathrm{kg}$ \\
Coal oil & $1.4714 \mathrm{kgce} / \mathrm{kg}$ \\
Diesel oil & $1.4571 \mathrm{kgce} / \mathrm{kg}$ \\
Fuel oil & $1.4286 \mathrm{kgce} / \mathrm{kg}$ \\
Coal tar & $1.1429 \mathrm{kgce} / \mathrm{kg}$ \\
Liquefied petroleum gas & $1.7143 \mathrm{kgce} / \mathrm{kg}$ \\
Oilfield natural gas & $1.33 \mathrm{kgce} / \mathrm{m}^{3}$ \\
Gas field natural gas & $1.214 \mathrm{kgce} / \mathrm{m}^{3}$ \\
Heat (equivalent value) & $0.03412 \mathrm{kgce} / \mathrm{MJ}$ \\
Electricity (equivalent value) & $0.1229 \mathrm{kgce} /(\mathrm{kW} \bullet \mathrm{h})$ \\
Electricity (equivalent) & - \\
\hline
\end{tabular}

Data source: General Principles for Calculation of the Comprehensive Energy Consumption (GB/T 2589-2008), https://www.cnis.ac.cn/pcindex/.

currently one of the most used models in the field of energy conservation and emission reduction. The calculation formula is

$$
t=\frac{\Delta E / E}{\Delta I / I}
$$

where $t$ represents the decoupling coefficient between tourism economic growth and industrial carbon dioxide emissions, $\Delta E / E$ represents the growth rate of carbon dioxide emissions of tourism, and $\Delta I / I$ represents the economic growth rate of tourism (this study uses income of tourism as an economic indicator). The decoupling relationship between tourism economic growth and carbon dioxide emissions of tourism can be divided into three types: negative decoupling, decoupling, and connection, and each type is refined into three indicators (see Table 2). Negative decoupling often means that the efficiency of energy conservation and emission reduction in the tourism industry is decreasing, that is, energy consumption per unit output value and carbon dioxide emissions are increasing. Decoupling often means that the energy-saving efficiency of the tourism industry is increasing, that is, energy consumption per unit output value and carbon dioxide emissions are decreasing. Connection means that the efficiency of energy conservation and emission reduction in the tourism industry is relatively stable, and energy consumption per unit output value and carbon dioxide emissions have not changed much.

\section{Results and Discussion}

3.1. Carbon Dioxide Emissions of Tourism in Heilongjiang Province. From formulas (3) and (4), the annual carbon dioxide emissions of tourism in Heilongjiang Province in $A$ and $B$ can be obtained, respectively, that is, the carbon dioxide emissions of the tourism industry in "Transport, Storage, and Post" and the tourism industry carbon dioxide emissions in "Wholesale, Retail Trade, and Catering Services." Then, we get the total carbon dioxide emissions from tourism in Heilongjiang Province by formula (2).
Figure 1 shows that from a time series perspective, the total carbon dioxide emissions of Heilongjiang Province's tourism industry and its components have shown a fluctuating growth trend from 2010 to 2019, increasing from 3.6 million tons in 2010 to 22.2 million tons in 2019. The total carbon dioxide emissions of tourism in Heilongjiang Province have been increasing for two consecutive years since 2010 and have been reduced year by year after 2012. It increased significantly in 2018 and maintained the same growth trend in 2019, which was 6 times the total carbon dioxide emissions of tourism in 2010.

In the past ten years, the difference between the carbon dioxide emissions of part $A$ and part $B$ of the tourism industry in Heilongjiang Province was relatively small, and the carbon dioxide emissions of part $A$ of the tourism industry accounted for more in the first five years. The fluctuation trend of the two is the same as the total carbon dioxide emission. Since 2015, the carbon dioxide emissions of Heilongjiang Province's tourism industry in part $A$ have continued to increase, and the carbon dioxide emissions in part $B$ have surpassed part $A$ in 2015 and show a trend of first decline and then increase. In 2018 and 2019, it exceeded the carbon dioxide emissions of tourism in part $A$ for two consecutive years.

Figure 2 shows that the total income of tourism in Heilongiiang Province from 2010 to 2019 has the same fluctuating trend as the carbon dioxide emissions of the tourism industry in part $A$, showing a slow growth, then a decline, and then a steady growth trend. The carbon dioxide emissions of the tourism industry in Heilongjiang Province in part $B$ have the same trend as income of tourism in the first five years, falling to 5.1 million tons in 2016, then rebounding in 2017, and significantly increasing to 9.2 million tons in 2018. Through SPSS software testing, the correlation coefficient between Heilongjiang's carbon dioxide emissions of tourism and income of tourism is 0.976 , which further proves that Heilongjiang's carbon dioxide emissions of tourism have a strong positive correlation with economic development.

Figure 3 shows that from the perspective of the combined analysis of tourism carbon emissions and economic development, through decoupling analysis, there are multiple decoupling relationships between carbon dioxide emissions and income of tourism in Heilongjiang Province from 2010 to 2019; expansive decoupling state appears four times, and weak decoupling state appears three times. From 2010 to 2016, the growth rate of Heilongiang's tourism industry's carbon dioxide emissions and income of tourism increased one after another. Among them, the tourism industry of Heilongjiang Province reached a state of strong decoupling in 2013, and the reduction in carbon dioxide emissions of tourism was accompanied by the increase of income of tourism. According to the Heilongjiang Statistical Yearbook, the statistical caliber of income of tourism in 2014 is different and incomparable with previous years. After the tourism industry in Heilongjiang Province reached a state where the growth rate of carbon dioxide emissions was equal to the growth rate of income of tourism in 2017, the former continued to be higher than the latter. From a long-term 
Table 2: Tapio carbon emission decoupling relationship index.

\begin{tabular}{|c|c|c|c|c|c|}
\hline Type & Index & $\Delta E$ & $\Delta I$ & $t$ & Implication \\
\hline \multirow{3}{*}{ Decoupling } & Strong decoupling & $<0$ & $>0$ & $<0$ & $\mathrm{CO}_{2}$ emissions reduced and income increased \\
\hline & Recession decoupling & $<0$ & $<0$ & $>1.2$ & $\begin{array}{c}\text { The reduction rate of } \mathrm{CO}_{2} \text { emissions is faster than the reduction rate } \\
\text { of income }\end{array}$ \\
\hline & Weak decoupling & $>0$ & $>0$ & $0<t<0.8$ & The increase in $\mathrm{CO}_{2}$ emissions is slower than the increase in income \\
\hline \multirow{2}{*}{ Connection } & Critical gl & $>0$ & $>0$ & $0.8<t<1.2$ & $\mathrm{CO}_{2}$ emissions are growing at the same rate as income \\
\hline & Critical decline & $<0$ & $<0$ & $0.8<t<1.2$ & $\mathrm{CO}_{2}$ emissions are declining at the same rate as income \\
\hline \multirow{3}{*}{$\begin{array}{l}\text { Negative } \\
\text { decoupling }\end{array}$} & $\begin{array}{l}\text { Weak negative } \\
\text { decoupling }\end{array}$ & $<0$ & $<0$ & $0<t<0.8$ & $\begin{array}{c}\text { The reduction rate of } \mathrm{CO}_{2} \text { emissions is slower than the reduction rate } \\
\text { of income }\end{array}$ \\
\hline & Expansive decoupling & $>0$ & $>0$ & $>1.2$ & The increase in $\mathrm{CO}_{2}$ emissions is faster than the increase in income \\
\hline & $\begin{array}{l}\text { Strong negative } \\
\text { decoupling }\end{array}$ & $>0$ & $<0$ & $<0$ & $\mathrm{CO}_{2}$ emissions increased and income reduced \\
\hline
\end{tabular}

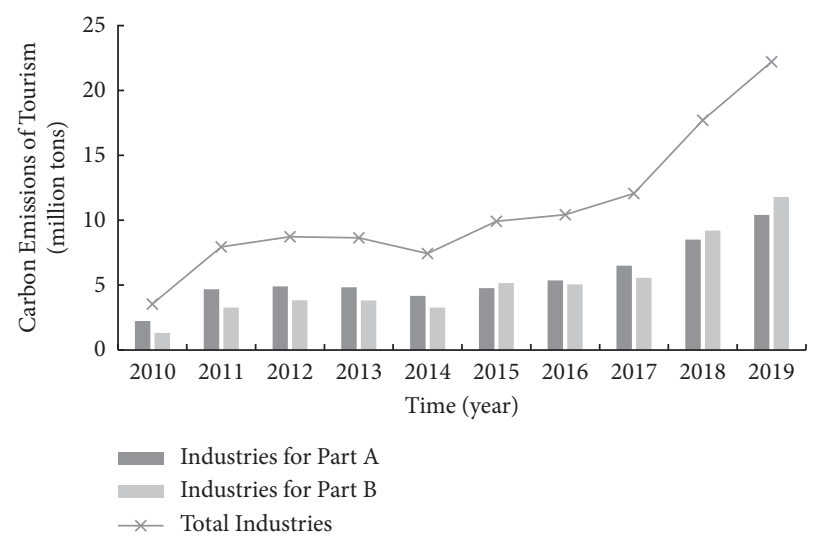

Figure 1: Carbon dioxide emissions of tourism in Heilongjiang Province.

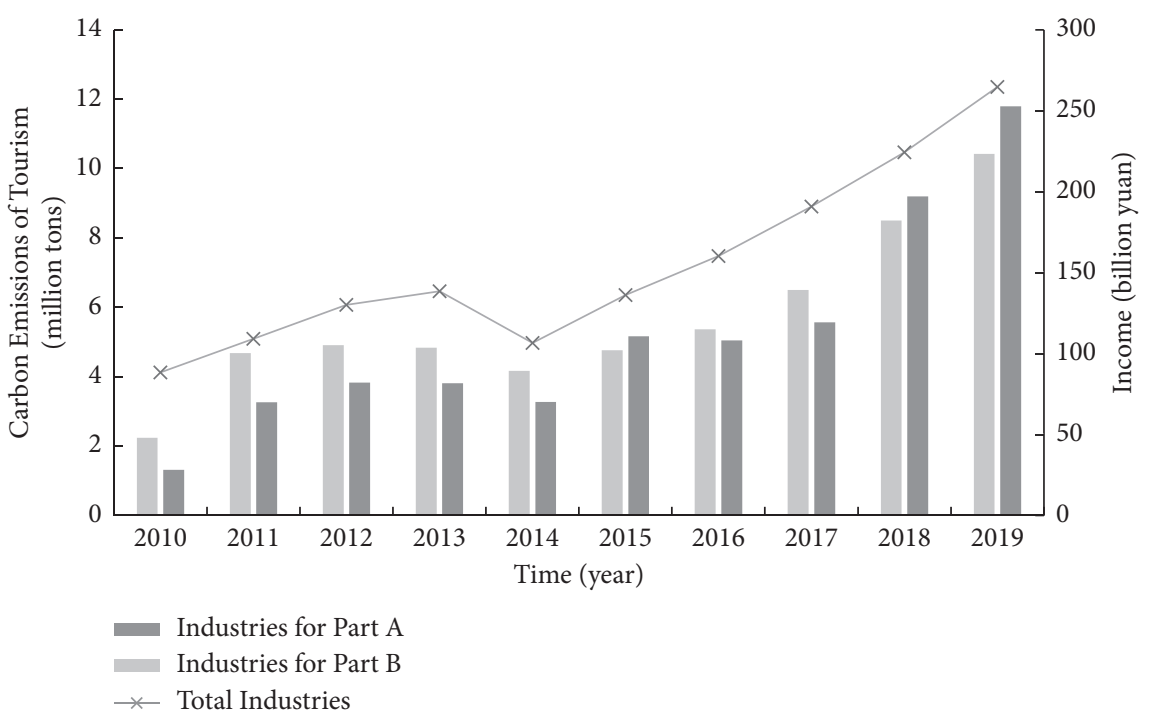

FIgURe 2: Income and carbon dioxide emissions of tourism in Heilongjiang Province.

perspective, the decoupling relationship between Heilongjiang's carbon dioxide emissions and economic growth of tourism is basically in a good state. From a short-term perspective, the decoupling relationship between Heilongjiang's carbon dioxide emissions and economic growth of tourism is unstable, with states weak decoupling and expansive decoupling appearing repeatedly. It can be seen that although the ideal state of strong decoupling between carbon dioxide emissions and income of tourism in Heilongiiang Province has reached an ideal state of strong decoupling, there is still space for improvement in Heilongjiang Province to maintain this state. 


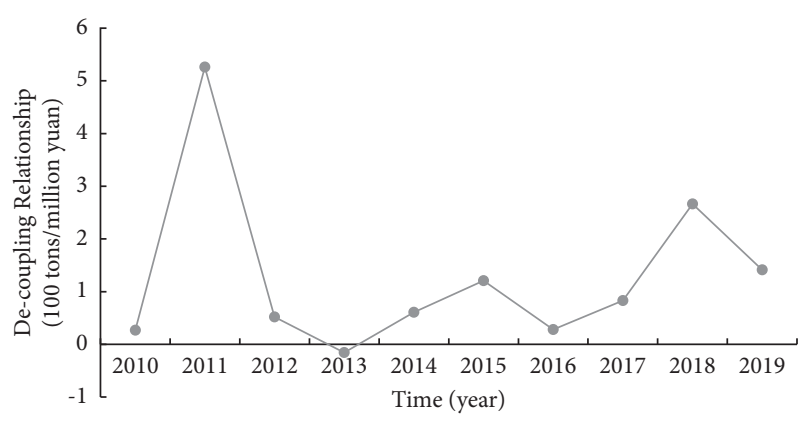

Figure 3: Decoupling relationships for Heilongjiang Province.

\subsection{Carbon Dioxide Emissions of Tourism in Regions.} From Figure 4, Harbin tourism's carbon dioxide emissions in part $A$ and part $B$ are both the largest among the twelve regions. The tourism industries of Kiamusze, Daqing, and Harbin have higher carbon dioxide emissions in part $B$, and the tourism industries of the other nine regions have higher carbon dioxide emissions in part $A$. The tourism industries of Qitaihe, Kiamusze, and Daqing have the same carbon dioxide emissions in the above two parts, while the tourism industries in the other regions have a large difference in carbon dioxide emissions in the two parts $A$ and $B$. The difference in carbon dioxide emissions between the two parts of Harbin tourism is $\mathbf{1 5 . 1}$ million tons. The difference in carbon dioxide emissions between the two parts of Heihe tourism is 6.8 million tons.

As can be seen from Figure 5, the carbon dioxide emissions of Heilongjiang's regional tourism industry in part A showed a fluctuating upward trend. From 2010 to 2016, the carbon dioxide emissions of Heilongjiang Province's regional tourism first increased, then decreased, and finally increased steadily. From 2017 to 2019, the carbon dioxide emissions of tourism in eleven other regions except Heihe have grown rapidly. During the ten years, the carbon dioxide emissions of Daqing tourism fluctuated greatly in the first five years, the carbon dioxide emissions of Harbin tourism fluctuated greatly in the next five years, and the carbon dioxide emissions of Qitaihe tourism were low and almost unchanged.

It can be seen from Figure 6 that the carbon dioxide emissions of Heilongjiang Province's regional tourism industry in part $B$ show a fluctuating upward trend overall. Harbin tourism has the most carbon dioxide emissions and is significantly higher than other regions. The carbon dioxide emissions of tourism in all regions increased significantly in 2011 and 2015 and have continued to increase in the past two years. From 2016 to 2017, except for Harbin's tourism industry, the growth rate of carbon dioxide emissions slowed down, and the others all declined. In the past ten years, the carbon dioxide emissions of Harbin tourism have increased rapidly, the carbon dioxide emissions of Daqing and Qiqihar tourism have fluctuated significantly, and the carbon dioxide emissions of Heihe and Qitaihe tourism have been low and almost unchanged.

Figure 7 and Table 3 show the proportion of the decoupling state between the carbon dioxide emissions of the regional tourism industry and the growth of income of tourism in Heilongjiang Province during the ten years. The more the decoupling state occurs, the better the region can coordinate the development of the tourism industry and the protection of the ecology. The frequency of decoupling in Suihua and negative decoupling in Harbin was the same, both being 6 times. Compared with other regions, Qitaihe and Jixi had fewer occurrences of ND, with the same number of 3 occurrences. Decoupling less frequently appeared in Hegang, but connected appeared 4 times. Harbin has a greater impact on the energy efficiency of tourism in Heilongjiang Province. Qitaihe and Jixi should invest more management and research on low-carbon tourism. Other cities need to pay more attention to low-carbon tourism.

\section{Discussion and Conclusions}

On the whole, from 2010 to 2019, the total carbon dioxide emissions of the tourism industry in Heilongjiang Province on "Transport, Storage, and Post" decreased from $63 \%$ to $47 \%$ of the total, and the tourism industry's total carbon dioxide emissions on "Wholesale, Retail Trade, and Catering Services" increased from $37 \%$ to $53 \%$. In the past ten years, the carbon dioxide emissions of Heilongjiang Province's tourism industry in part A have surpassed the carbon dioxide emissions of part B in seven years, indicating that part A still has a greater influence on the carbon dioxide emissions of Heilongjiang Province's tourism industry. However, the carbon dioxide emissions of the tourism industry in part $B$ exceeded the carbon dioxide emissions of part $A$ in 2015 and the past two years, and the increase in carbon dioxide emissions from the tourism industry was faster than the increase in income of tourism. It can be seen that the development focus of Heilongjiang Province's tourism industry is tilted towards wholesale, retail, accommodation, and catering industries. This is followed by an increase in energy consumption and carbon dioxide emissions. Although the tourism industry in Heilongjiang Province has gradually formed a green development mode and lifestyle, the green ecological industry has developed rapidly, the total discharge of major pollutants has been significantly reduced, and the air quality in the city has been significantly improved. However, the total carbon dioxide emissions of the tourism industry are showing an upward trend as a whole. While promoting the development of tourism from multiple angles and fields, the development environment still needs to be vigorously optimized.

From the perspective of economic development, the decoupling relationship between carbon dioxide emissions and economic growth of tourism in Heilongiiang Province from 2010 to 2019 is basically in good condition. It shows that energy-saving and emission-reduction measures have achieved certain results in the development of the province's tourism industry. While vigorously developing the economy, Heilongjiang Province also pays attention to protecting the environment. In the short term, the decoupling relationship between Heilongjiang's carbon dioxide emissions and economic growth of tourism is unstable. Among them, the four years of tourism in Heilongjiang Province have seen 


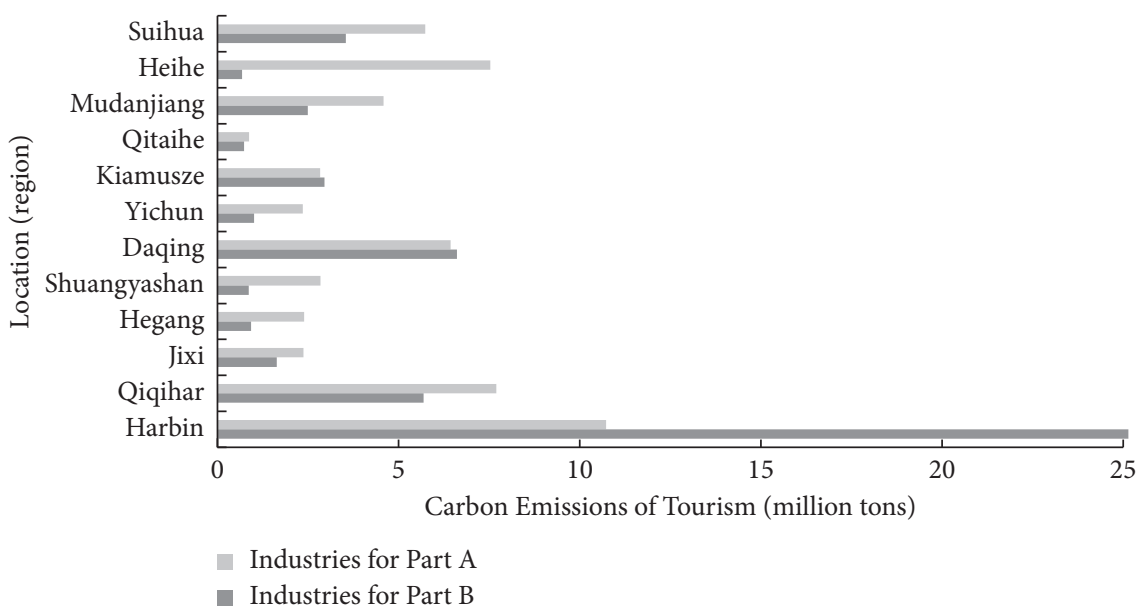

Figure 4: Carbon dioxide emissions in regional tourism.

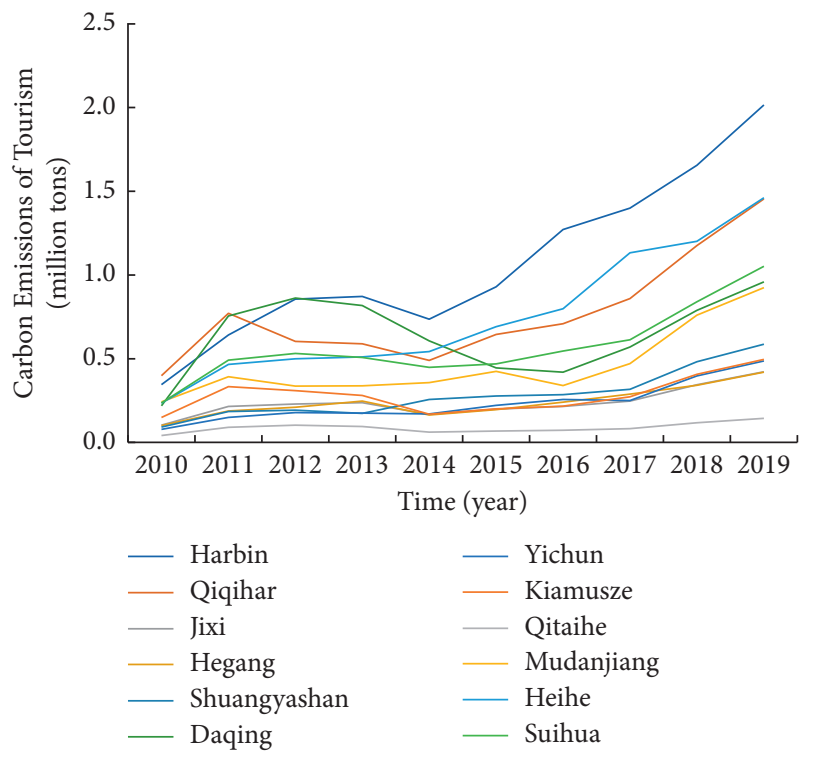

Figure 5: Carbon dioxide emissions of regional tourism in "Transport, Storage, and Post."

a high rate of increase in carbon dioxide emissions from tourism. It shows that Heilongjiang Province's economic aggregate has been expanding and its structure has been optimized in recent years. It also has achieved remarkable results in cultivating new kinetic energy and new growth areas. While vigorously developing the economy, it has strengthened ecological protection, and straw can be comprehensively used.

From a regional perspective, the tourism industry in Harbin at Part B has significantly higher carbon dioxide emissions than in other regions from 2010 to 2019, indicating that the economic development of regional tourism in Heilongjiang Province is unbalanced, and the tourism industry in some areas is still not very attractive. In 2018 and 2019, there were 11 regions in Heilongjiang Province where the carbon dioxide emissions of tourism in part $A$ increased rapidly, and the carbon dioxide emissions of tourism in all regions in part $B$ continued to increase in the past two years. It shows that as the overall tourism industry in Heilongjiang Province has been significantly improved in economic growth, energy consumption has not received sufficient attention in management and control. The strong decoupling between carbon dioxide emissions and economic growth of tourism has not been maintained.

The tourism industry's carbon dioxide emissions have been a topic of concern in recent years. This study has made preliminary attempts and explorations in the measurement of tourism industry's carbon dioxide emissions. There are still many shortcomings in the research, and there are many aspects that need to be explored and improved in future research. Due to the limited data sources, this study only measures the carbon dioxide emissions of the tourism industry in Heilongjiang Province of China from the time series and spatial perspectives and analyses the decoupling relationship between the carbon dioxide emissions of the regional tourism industry and economic growth. The carbon dioxide emissions of scenic spots in Heilongjiang Province cannot be measured. In addition, as a popular ice and snow tourist destination in Heilongjiang Province, the tourism industry is greatly affected by the seasons. The follow-up research can also measure the seasons from a time series perspective. This study is only an estimate of the current situation. The focus of the next step of the study should be to estimate the future energy consumption and carbon dioxide emission scenarios of the tourism industry under the premise of improving the accuracy of the estimate, so as to enhance the practical guiding significance of this research.

\section{Suggestions}

This study estimates the carbon dioxide emissions from tourism in Heilongjiang Province and its region from 2010 to 2019 by industry. From the perspective of time series, the changes in the carbon dioxide emissions of the tourism industry in Heilongjiang Province in the past ten years and the decoupling relationship with economic growth are measured. From the perspective of space, we compare the consumption of carbon dioxide emissions of tourism by 


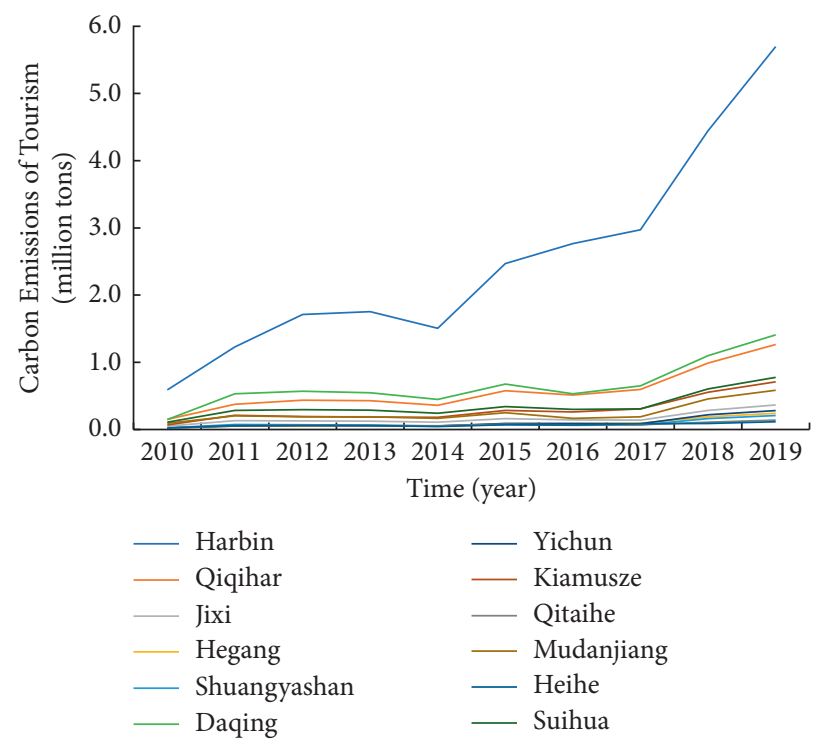

Figure 6: Carbon dioxide emissions of regional tourism in "Wholesale, Retail Trade, and Catering Services."

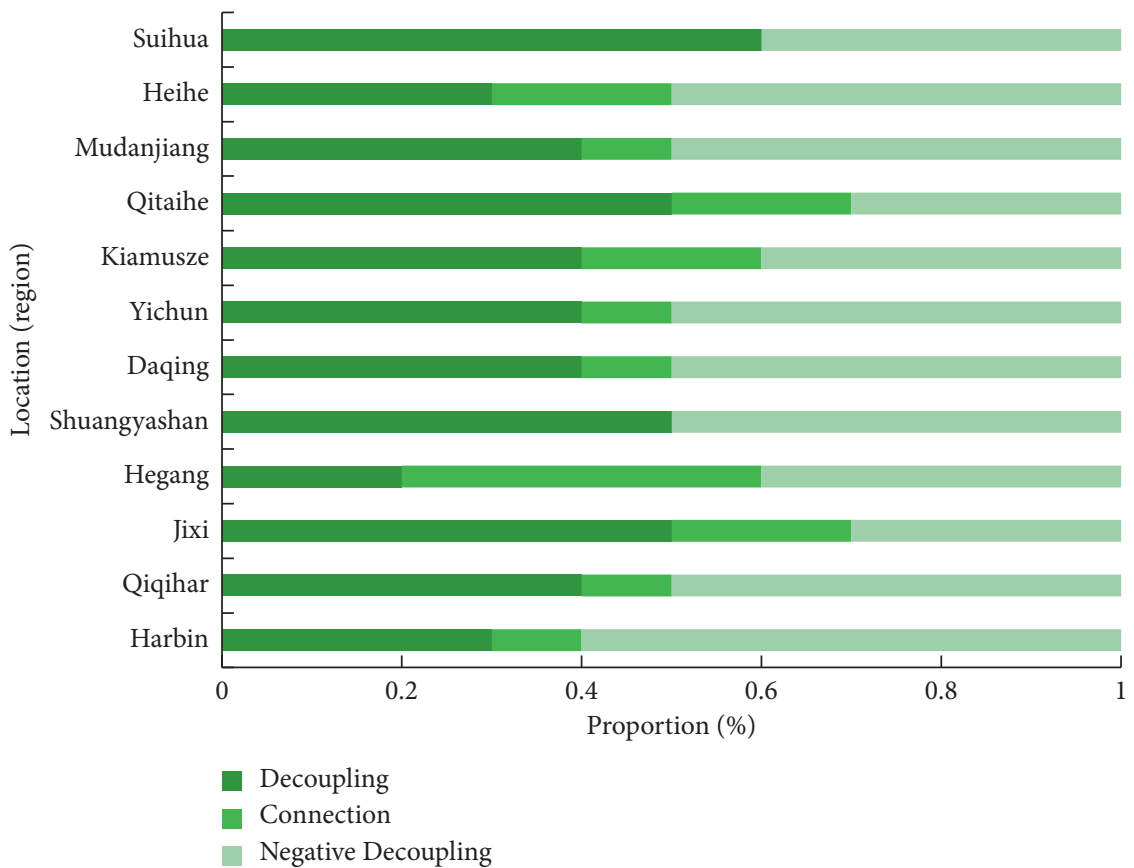

FIGURE 7: Decoupling relationships for regional tourism.

industry among regions. The research results provide an objective basis for the future implementation of energy conservation and emission reduction in Heilongjiang Province and the regional tourism industry.

This research aims to provide feasible suggestions and countermeasures for the development of tourism in Heilongjiang Province and its region and to provide an objective basis for the implementation of energy conservation and emission reduction in the tourism industry in Heilongjiang Province and cities in the future. It can be seen that energysaving and emission-reduction measures have continued to achieve results in the development of Heilongjiang's tourism industry, but the trend of change is unstable, indicating that the government should focus on reducing overall carbon dioxide emissions from a technical and management perspective. Compared with the research results of other scholars, it can be seen that the tourism industry in Heilongjiang Province has been improving year by year in the promotion of low-carbon tourism in the past ten years. follows: 
TABle 3: Decoupling coefficient for regional tourism.

\begin{tabular}{|c|c|c|c|c|c|c|c|c|c|c|}
\hline \multirow{2}{*}{ Region } & \multicolumn{10}{|c|}{ Year } \\
\hline & 2010 & 2011 & 2012 & 2013 & 2014 & 2015 & 2016 & 2017 & 2018 & 2019 \\
\hline Harbin & 0.05 & 3.9 & 1.95 & 0.31 & 0.66 & 1.72 & 0.97 & 0.42 & 2.25 & 1.44 \\
\hline Qiqihar & 0.72 & 5.01 & -0.50 & -0.36 & 0.7 & 1.53 & -0.004 & 0.98 & 3.99 & 1.43 \\
\hline Jixi & 0.46 & 5.86 & 0.1 & 0.21 & 0.96 & 1.16 & -0.03 & 0.40 & 4.83 & 1.43 \\
\hline Hegang & 0.17 & 4.59 & 0.46 & 4.93 & 1.06 & 1.19 & 1.02 & 0.98 & 1.22 & 1.40 \\
\hline Shuangyashan & 0.73 & 6.29 & 0.13 & -2.32 & -1.24 & 0.53 & -0.05 & 0.61 & 2.58 & 1.38 \\
\hline Daqing & 0.23 & 9.63 & 0.59 & -0.68 & 0.98 & 0.28 & -1.05 & 1.58 & 3.97 & 1.39 \\
\hline Yichun & -0.16 & 5.33 & 0.83 & -0.46 & 0.15 & 1.52 & 0.63 & -0.19 & 2.57 & 1.41 \\
\hline Kiamusze & 0.07 & 6.76 & -0.4 & -1.25 & 1.06 & 1.35 & -0.09 & 1.12 & 2.54 & 1.46 \\
\hline Qitaihe & 0.33 & 6.41 & 0.53 & -2.28 & 0.99 & 1.11 & -0.3 & 0.57 & 121.23 & 1.42 \\
\hline Mudanjiang & 0.05 & 3.31 & -0.73 & 0.04 & 0.06 & 1.02 & -1.3 & 1.51 & 5.63 & 1.36 \\
\hline Heihe & 0.62 & 6.14 & 0.31 & 0.39 & -0.13 & 1.18 & 0.87 & 2.44 & 25.63 & 1.41 \\
\hline Suihua & 0.5 & 5.99 & 0.31 & -0.59 & 0.59 & 0.62 & 0.23 & 0.48 & 4.48 & 1.43 \\
\hline
\end{tabular}

(1) In terms of hotel management in the tourism industry, green hotels should be selected to reduce the use of resources and energy and the generation of pollutants. Direct energy conservation and emission reduction can be achieved by improving technology and management behaviour to increase energy efficiency and reduce unit energy consumption. Indirect energy saving and emission reduction can be achieved by adjusting the production structure and product structure and improving labour productivity.

(2) In terms of transportation in the tourism industry, the main direction of energy conservation and emission reduction is to pay attention to the use of transportation vehicles and vigorously promote green tourism transportation. The authorities should guide and encourage tourists to use lowcarbon public transportation, such as subways, buses, urban public bicycles, and so on. Heilongjiang Province should change the past highcarbon dioxide emission energy use and consumption structure and effectively reduce the intensity of carbon dioxide emissions in various sectors of the tourism industry, in order to achieve the ideal strong decoupling relationship between Heilongjiang's carbon dioxide emissions and economic growth of tourism.

(3) In terms of technological innovation in the tourism industry, regional tourism-related enterprises should increase the research and utilization of low-carbon technologies to promote the development of lowcarbon technologies. At present, China's low-carbon technology has achieved certain results, but due to the large regional differences in China, the applicability of the corresponding technology is not good. While introducing advanced technologies, the proportion of clean energy sources such as solar energy, hydropower, and biomass should be increased. At the same time, in order to realize the green and sustainable growth of the tourism economy in Heilongjiang Province, relevant departments should independently research and develop low-carbon emission-reduction technologies suitable for regional needs. Related industries should also actively cooperate with local universities, increase investment in related scientific research, and increase research on the development and utilization of new tourism energy and the recycling of tourism waste.

(4) In terms of policy improvement in the tourism industry, governments, social organizations, tourismrelated enterprises, and so on should actively advocate concepts such as low-carbon consumption. Through the promotion of low-carbon tourism in Heilongjiang Province and the development of lowcarbon tourism scenic spots, tourists are guided to choose environmentally friendly transportation.

There is a large gap in tourism development between Heilongjiang Province and its regions, accompanied by slow development of tourism resources and uneven development of 12 regions. The improvement of the tourism system is the top priority for the overall balanced development of Heilongjiang's tourism industry in the future. The authorities of Heilongjiang Province still need to focus on planning the layout of related industries in their tourism industry. For example, the relevant departments have gradually realized the sustainable development of the tourism industry in Heilongjiang Province through measures such as promoting the ecological culture of the regional tourism industry, so as to reach and maintain the strong decoupling state as soon as possible.

\section{Data Availability}

The data are available upon request to the corresponding author at tz09@163.com.

\section{Conflicts of Interest}

The authors declare that they have no conflicts of interest.

\section{Acknowledgments}

This research was supported by the National Natural Science Foundation of China (grant no. 41801137), China Postdoctoral Science Foundation (grant no. 2016M600257), 
Postdoctoral Program of Heilongjiang Province (grant no. LBH-Z16093), Projects of Philosophy and Social Sciences of Heilongjiang Province (grant nos. 20JYE275 and 19JYE271), Doctoral Research Projects of Harbin University of Commerce (grant no. 2016BS05), Young Innovative Talents Project of Harbin University of Commerce (grant nos. 2019CX19 and 18XN013), and Graduate Innovative Research Project of Harbin University of Commerce (grant no. YJSCX2020-655HSD).

\section{References}

[1] IPCC, AR6 Climate Change 2021: The Physical Science Basis, IPCC, Geneva, Switzerland, 2021.

[2] A. Mardani, D. Streimikiene, F. Cavallaro, N. Loganathan, and M. Khoshnoudi, "Carbon dioxide $\left(\mathrm{CO}_{2}\right)$ emissions and economic growth: a systematic review of two decades of research from 1995 to 2017," The Science of the Total Environment, vol. 649, pp. 31-49, 2018.

[3] S. Gössling, "Global environmental consequences of tourism," Global Environmental Change, vol. 12, no. 4, pp. 283-302, 2002.

[4] J. P. Xi, "Statement at the general debate of the 75th session of the united nations general assembly," Gazette of the State Council of the People's Republic of China, vol. 28, pp. 5-7, 2020.

[5] Heilongjiang Bureau of Statistics, Heilongjiang Statistical Yearbook 2020, China Statistics Press, Beijing, China, 2021.

[6] M. Azam, M. Mahmudul Alam, and M. Haroon Hafeez, "Effect of tourism on environmental pollution: further evidence from Malaysia, Singapore and Thailand," Journal of Cleaner Production, vol. 190, pp. 330-338, 2018.

[7] P. Wu and P. Shi, "An estimation of energy consumption and $\mathrm{CO} 2$ emissions in tourism sector of China," Journal of Geographical Sciences, vol. 21, no. 4, pp. 733-745, 2011.

[8] J. P. Zha, H. Y. Shu, Y. Y. Li, and L. M. He, "A Research on tourism industrial carbon emissions and its influential factors in China: evidences from Chinese Provincial panel data (2005-2015)," Tourism Science, vol. 31, no. 5, pp. 1-16, 2017.

[9] Z. Tang, S. Z. Bai, C. B. Shi, L. Liu, and X. H. Li, "Tourismrelated $\mathrm{CO}_{2}$ emission and its decoupling effects in China: a spatiotemporal perspective," Advances in Meteorology, vol. 2018, Article ID 1473184, 9 pages, 2018.

[10] L. N. Hu and H. Y. Hu, "Research on the changes of tourism carbon dioxide emissions and the decoupling relationship with the economic growth of Tibet," Journal of Tibet University, vol. 34, no. 4, pp. 185-192+208, 2019.

[11] X. C. Zhao and X. Zhu, "A rough estimation of $\mathrm{CO}_{2}$ emission and analysis of decoupling effects in tourism sector of Hunan," World Regional Studies, vol. 22, no. 1, pp. 166-175 + 129, 2013.

[12] H. Hu, J. H. Zhang, M. Yang, J. Y. Kang, and J. K. Sun, "Measuring $\mathrm{CO}_{2}$ emissions and studying on dynamic changes for regional tourism: a case study of Jiangsu Province," Ecological Economy, vol. 32, no. 6, pp. 57-62, 2016.

[13] Q. Wang, J. Y. Li, and Z. L. He, "The study of measurement and calculation of carbon emission and decoupling relationship of tourism industry in Xinjiang," Ecological Economy, vol. 34, no. 1, pp. 25-30, 2018.

[14] Y. J. Han and P. Wu, "The measurement and comparative study of carbon dioxide emissions from tourism industry of Beijing-Tianjin-Hebei," Human Geography, vol. 31, no. 4, pp. 127-134, 2016.
[15] J. A. Coopera and B. P. McCulloughb, "Bracketing sustainability: carbon footprinting March Madness to rethink sustainable tourism approaches and measurements," Journal of Cleaner Production, vol. 318, Article ID 128475, 2021.

[16] A. Gühnemann, A. Kurzwei, and M. Mailer, "Tourism mobility and climate change-a review of the situation in Austria," Journal of Outdoor Recreation and Tourism, 2021, in press, Article ID 100382.

[17] N. M. Saviolidis, D. Cook, B. Davíðsdóttir, L. Jóhannsdóttir, and S. Ólafsson, "Challenges of national measurement of environmental sustainability in tourism," Current Research in Environmental Sustainability, vol. 3, Article ID 100079, 2021.

[18] V. Filimonau, J. Dickinson, D. Robbins, and M. V. Reddy, "The role of "indirect" greenhouse gas emissions in tourism: assessing the hidden carbon impacts from a holiday package tour," Transportation Research Part A: Policy and Practice, vol. 54, pp. 78-91, 2013.

[19] A. Paiano, T. Crovella, and G. Lagioia, "Managing sustainable practices in cruise tourism: the assessment of carbon footprint and waste of water and beverage packaging," Tourism Management, vol. 77, Article ID 104016, 2020.

[20] J. Kelly and P. W. Williams, "Modelling tourism destination energy consumption and greenhouse gas emissions: Whistler, British Columbia, Canada," Journal of Sustainable Tourism, vol. 15, no. 1, pp. 67-90, 2007.

[21] Y. Y. Sun, "Estimation of $\mathrm{CO}_{2}$ emission and its effect decomposition in tourism sector of Shanghai City," Areal Research and Development, vol. 39, no. 1, pp. 122-126, 2020.

[22] Q. R. Wang and F. L. Xie, "Urban tourism situation analysis on $\mathrm{CO}_{2}$ emissions and future low carbon scenarios based on decoupling theory and Kaya identities," Tourism Tribune, vol. 29, no. 8, pp. 98-109, 2014.

[23] G. H. Zhang and J. Liu, "Analysis on decoupling relationship between tourism development and carbon emission in coastal region of China," Resource Development \& Market, vol. 31, no. 11, pp. 1352-1357, 2015.

[24] S. Akadiri, G. Uzuner, A. Akadiri, and T. T. Lasisi, "Environmental Kuznets curve hypothesis in the case of tourism island states. The moderating role of globalization," International Journal of Finance \& Economics, vol. 26, no. 3, 2020.

[25] K. Wang, J. Li, and J. C. Xi, "Linking between carbon dioxide emission and tourism economic growth in China," Tourism Tribune, vol. 29, no. 6, pp. 24-33, 2014.

[26] J. Ma, F. M. Qin, and X. Xie, "Decoupling the inbound tourism carbon emissions of the tourism economic growth," Journal of Xinjiang University (Philosophy, Humanities \& Social Sciences), vol. 47, no. 2, pp. 16-23, 2019.

[27] P. Tzeremes, "Does the environmental Kuznets curve exist in the Chinese regions?" Global Economic Review, vol. 48, no. 4, pp. 363-377, 2019.

[28] Y. F. Xie and Y. Zhao, "Measuring carbon dioxide emissions from energy consumption by tourism in yangtze river delta," Geographical Research, vol. 31, no. 3, pp. 429-438, 2012.

[29] J. F. Li and M. Y. Li, "On the calculation of tourism industry and tourist adding value," Tourism Tribune, vol. 14, no. 5, pp. 16-19+76, 1999 .

[30] P. Tapio, "Towards a theory of decoupling: degrees of decoupling in the EU and the case of road traffic in Finland between 1970 and 2001," Journal of Transport Policy, vol. 12, no. 12, pp. 137-151, 2005.

[31] OECD, Indicators to Measure Decoupling of Environmental Pressure from Economic Growth, OECD, Paris, France, 2002, http://www.olis.oecd.org/olis/2002doc.nsf/LinkTo/sg-sd. 